\title{
R\&D and Standardisation Activities of High Technology Industries in Japan in the Information and Communications Technology Services Field
}

\author{
Suguru Tamura \\ Waseda University, GITS/Comprehensive Research Organization \\ Nishi-waseda Shinjuku-ku, Tokyo, Japan
}

\begin{abstract}
This study aims to elucidate the relationship between Research and Development $(R \& D)$ and standardisation of Information and Communications Technology (ICT) services in high technology industries of Japan. The study focuses on Intellectual Property (IP) standardisation activities as a key factor in corporate innovativeness. The author examines the magnitude of the effects of $R \& D$ and standardisation on patent applications in the Japanese electric machinery industry, which provide ICT services and includes the electric appliance manufacturers. The number of patent applications is known to have a positive impact on corporate innovativeness and can be used as a proxy for determining this magnitude of the impact. Pearson correlation coefficient between the number of persons engaged in IP standardisation activities and the number of patent applications is found to be positive, but smaller in comparison with the number of persons engaged in $R \& D$ activities. However, the impact of standardisation is larger than what is generally anticipated. These findings might assist corporate managers in decision making pertaining to allocating human resources.
\end{abstract}

Keywords: Standardisation, Research and Development (R\&D), Patents, Intellectual Property (IP), Innovation.

\section{INTRODUCTION}

I $\mathrm{n}$ the 21st century, standardisation plays an important role in a wide variety of areas of innovation, including both products and services. In this research paper, the role of standardisation is measured in the Japanese electric machinery industry. Presently, the industry provides a wide range of ICT appliances and ICT-related services, including cellular phones and tablet computers. The electric machinery industry has a strong connection to ICT services. The effects of standardisation on the industry are presumed to be a fairly good indicator for measuring the effects of the standards on both ICT services and ICT manufacturing.

From the broad array of comprehensive standardisation activities undertaken by corporations worldwide, this research paper focuses on standardisation within the realm of IP management. The reason why IP management is important to corporations can be illustrated by the case of the

Journal of Technology

Management for Growing Economies

Vol. 4 No. 2 Oct 2013 pp. $67-83$

\section{ChITKARA 司 UNIVERSITY}

CC2013 by Chitkara University. All Rights Reserved. 

of the American National Standards Institute (ANSI), a standardisation body, correlates with patent granting in the modem industry from the 1990s to the 2000s in the United States (Gandal et al, 2007). This research paper also examines the effects of R\&D and standardisation activities on corporate innovativeness in the ICT services industry. The methodology involves using the Pearson correlation coefficient for analysing various factors.

In the modern world, standardisation of novel technologies and services, which are the result of corporate $\mathrm{R} \& \mathrm{D}$ activities, is an important aspect of innovation. It is reported that standardisation will promote product development with large impact (Tamura and Matsuda, 2008). Today many types of standards, from ICT services standards to product-related standards, are formulated in international forums such as the International Organization for Standardization (ISO) and the International Telecommunication Union (ITU). However, the relationship between R\&D and standardisation has not been comprehensively discussed from a quantitative viewpoint, and arguments concerning the relationship tend to be based upon intuition. It is astonishing that the number of people working on standards is not measured universally, whereas the number of persons working on patents has been measured for a half century. Statistical analysis of the applicable factors has not been conducted to gain a mathematical understanding of this relation. The knowledge gained from such analysis would enable policymakers as well as business managers, to understand the relationship quantitatively, rather than solely relying on the prevailing intuitive arguments that have clouded the subject so far.

For instance, data only on limited types of output factors, such as the current number of de jure standards, are available (International Organization for Standardization, 2006). Data on input factors such as capital and human resources have not yet been provided and a suitable measurement method is still undeveloped. A possible explanation for this apparent lack of progress is that corporate standardisation activities are difficult to measure by a simple headcount because such activities are usually conducted by staff as supplementary work in addition to their core duties. Despite this limitation, the headcount method is still widely used to determine the magnitude of standardisation activities conducted. It is hence necessary to develop appropriate data collection methods for the determination of standardization activities.

Currently, various administrative forums for science and innovation policy, such as the Organisation for Economic Co-operation and Development 
(OECD), have not yet fully studied the standardisation issue. Furthermore, most related researches focus only narrowly on the activities of Standard Development Organisations (SDOs) such as ISO and ITU rather than on activities conducted within corporations. Therefore, unlike the case of IP strategy and corporate R\&D strategy, the relationship between standardisation and corporate $\mathrm{R} \& \mathrm{D}$ activity has not been fully elucidated.

Another importance aspect to be considered is the magnitude of R\&D and standardisation activities on corporate innovation. If the relation turns out to be clear, corporations can allocate scarce capital resources more effectively including human capital. For example, if a greater effect were observed for standardisation activities than for R\&D activities, it would be advantageous for corporations to devote more human resources to standardisation activities than at current levels.

For this study, data was extracted from Japan Patent Office (JPO). Data on standardisation related activities (SRA) in the context of IP activities within corporations were released by the JPO in early 2008. Since 2002, the JPO has conducted the 'Survey of IP-Related Activities'(SIPRA) in an effort to monitor IP activity trends. The survey covers both input and output factors affecting IP-related activities (IPRA) within corporations. For the output, data is collected on the number of patent applications submitted while for the input data is collected on human resources participating in $R \& D$ and IP activities. In the original survey form, the topic of standardisation was not included, but was included in the beginning of 2008, the JPO added a survey question to capture input data on SRA, specifically, the number of persons engaged in IP-related standardisation activities (PIPRSA). Analysis of data obtained in 2008 revealed a significant positive correlation between standardisation and corporate innovativeness within the Japanese electric machinery industry (Tamura, 2010). Furthermore, data in the SIPRA on the number of R\&D personnel working within corporations have enabled evaluation of how $R \& D$ and standardisation affect corporate innovativeness, thereby opening the door to new avenues of research.

Since, it is difficult to measure all standardisation activities within any corporation, the focus in this study emphasises only on standardisation activities that occur within IP, as opposed to all standardisation activities conducted within a corporation. Here, the variables of IP activities, R\&D activities and standardisation activities within the IP realm are represented by the number of persons engaged in an activity as reported in the SIPRA.
$\mathrm{R} \& \mathrm{D}$ and Standardisation 
Tamura, S.

\section{RESEARCH OBJECTIVES}

The research described in this paper has three objectives.

\section{Objective 1}

- To quantify the impact of number of persons engaged in standardisation activities on the number of patent applications

This will show the validity of standardisation in explicit numerical terms, and is thus preferable to an intuitive understanding.

Objective 2

- To compare the impact of number of persons working in R\&D and number of persons working on standardisation of patent applications

This should throw light on the impact of standardisation activities and may be useful in allocating human resources between standardisation activities and R\&D activities within an organisation.

\section{Objective 3}

- To compare the different impacts of standardisation on patent applications between industries; the electric machinery industry in particular

This evidence will be useful for planning R\&D strategy, because the electric machinery industry contributes a large amount to economic growth and invests significant sum of money on R\&D in many countries.

To achieve these three objectives, this research paper focuses on Pearson correlation coefficient analysis rather than multiple regression analysis, since the development of evaluation equations and detection of cause and effect among these three factors are not in the scope of this research's analysis.

The remainder of the paper is organised as follows. Review of literature is discussed in the next section. This is followed by the methodology section, which presents and explains the methodology behind the analysis including the dataset composition, hypotheses along with related background information. Further on the results of the analysis are presented which is followed by discussion, conclusion and implications. The last section discusses the limitations of this research and potential areas for further research followed by the list of abbreviations.

\section{LITERATURE REVIEW}

This section describes the methodological framework and background 
information to improve the understanding of this research paper and to demonstrate the novelty of this research. Since this area of research is still developing there is a lack of relevant documentation (Blind and Jungmittag, 2008) and most of the researches are carried out on a trial-and-error basis.

\section{Basic Framework}

It has been previously pointed out that there are not enough institutions gathering statistical information across the globe and also the international organisations are not well equipped to gather statistical information relating to standards (Tamura, 2012). However, in case of Japan, at least, the following data collection system is in place through which data are being accumulated.

\section{SIPRA Data and Definitions}

\section{i) Outline}

This research work utilises raw data from the SIPRA covering fiscal year 2008. The SIPRA, which has been published by JPO annually since 2002, collects data on individuals, companies, universities and research institutes to facilitate effective IP policymaking in Japan.

ii) Survey objectives

SIPRA targets entities that have made at least five applications in Japan for patents, utility model registrations, design registrations, or trademark registrations in the previous year. Out of the 7,608 eligible participants surveyed in 2008, the JPO received 3,375 responses in total (response rate: $45.4 \%$ ).

iii) Definitions

A standard is defined by Stango (2004) as 'specifications that determine the compatibility of different products'. However, this definition focuses on the output side of standardisation activities for products or services. In the present research, the definition includes measurement of input, such as the amount of labour used for such activities. Therefore, the following definition are used which covers the work of standardisation at various stages viz., negotiation in the front office, planning in the middle office and support in the back office (Japan Patent Office, 2008).

\section{a) Definition of standardisation-related activities (SRA)}

In the SIPRA survey, SRA includes

(1) Formation of standards or amendments to a certain technology amongst multiple relevant parties:

(2) Negotiations for the drafting of technology standards by international or

Journal of Technology Management for Growing Economies, Volume 4, Number 2, Oct 2013 
Tamura, S. domestic committees

(3) Management and support of standards. Under the definition used by the Japan Patent Office (2008), formation and amendment refers to the simplification and unification of technical specifications, measurement and inspection methods, and technological terms or symbols.

b) Definition of persons engaged in IP-related standardisation activities (PIPRSA)

PIPRSA is defined as an individual who engages in

(1) Research of patents for related standards, evaluation of licensing negotiations for essential patents, draft preparation and submission of patent statements in relation to standardisation, responses to patent infringement claims relating to technology standards, and standards related planning, management, research, evaluation and other related activities;

(2) The proposal of standards, the standard deliberation process, and domestic and international standard-related negotiation; and

(3) Supporting activities for standardisation, such as education, public promotion, accounting, general affairs and other tasks (Japan Patent Office, 2008).

c) Definition of persons engaged in IP-related activities(PIPRA)

Here, PIPRA is defined as an individual who engages in

(1) The acquisition, maintenance or mining of industrial patents, the management of IP and the evaluation of IP rights;

(2) Negotiations of license agreements, transactions and dispute settlements of IP rights; and

(3) Support functions for IP-related activities such as planning, investigation, education, accounting, general affairs and other related activities (Japan Patent Office, 2008).

d) Definition of $R \& D$ personnel

R\&D personnel are defined as individuals who engage in research activities and general administrative, accounting and other maintenance activities (Japan Patent Office, 2008).

e) Definition of $R \& D$ activities

R\&D activities are defined as essential activities carried out

(1) In research centres and research departments, where activities include

Journal of Technology Management for Growing Economies, Volume 4, Number 2, Oct 2013 
thinking, considering, collecting information and materials, test sampling, experimenting, inspecting, analysing and reporting of results;

$\mathrm{R} \& \mathrm{D}$ and

(2) In manufacturing sites such as factories, where activities include preparing, designing, fabricating and assessing pilot plants and prototype models; and

(3) General administrative and accounting work to support all such activities (Japan Patent Office, 2008).

iv) Counting method

a) Estimates of PIPRA and PIPRSA

The survey determines the number of PIPRA, PIPRSA and R\&D personnel on an FTE basis as opposed to using headcount method. Although, both headcount and FTE can be used to measure the number of persons engaged in a specific activity, the Frascati Manual of the OECD recommends FTE for counting researchers and scientists (Organisation for Economic Co-operation and Development, 2002).

\section{b) Number of patent applications}

Both the number of patent applications and utility model applications are counted as patent applications in the survey. In this research paper, the term 'patent application' is used to denote both the categories.

\section{The Nature of Standardisation and Corporate Innovativeness}

Historically, the effect of standards on innovation has caused various arguments. A famous case study is the QWERTY keyboard (David, 1985). In this case, the standards hindered product innovation. The keyboard arrangement on modern personal computers and even tablet PCs is the same as the mechanical typewriter of a century ago. Efficient key arrangements have been proposed over the past century, but new and effective keyboard arrangements have failed to take hold because of the lock-in effect of the old QWERTY keyboard arrangement. This implies that standards have a negative effect on innovation. However, this analysis concentrates on only one product (i.e. keyboards) and depends on the case-study method, rather than a quantitative perspective.

Statistical research on the relationship between corporate innovativeness and standardisation is still an emerging subject of research. One of the reasons is that data on standardisation activities within corporations are scarce. Because of this, the benefits afforded by standardisation and effects on corporate strategy have not been clarified thus far. As such, corporations and government are not motivated to measure the value of standardisation. Standardisation activities are seen as a cost to corporations; for example, attending standard 

directly benefit corporation by providing profit, they are simply seen as an expense by many corporations. Thus, corporations often place a low value on standardisation activities. Consequently, few studies have been undertaken in this important field of study.

However, recent studies involving the numerical analysis of standardisation work have garnered some attention. In an examination of standardisation activities in SDOs such as ANSI, Gandal et al (2007) showed that a significant positive correlation exists in the American electric machinery industry between the number of participants in an SDO and the number of patents granted. This finding implies participation in an SDO will benefit the conceptual formation of patents. This finding suggests a positive effect of standardisation activities on corporate innovativeness. Similarly, for patent applications, Tamura (2010) reported a positive correlation between the number of patent applications and standardisation activities within IP activities of the corporate.

The opinion of persons engaged in industrial R\&D indicates that standards have a greater impact on industry than on academic research (Tamura and Matsuda, 2008). This means that standardisation is more useful for corporate R\&D strategy than is generally understood and that the information about the development of new standards is as important as information about R\&D activities.

Furthermore, a recent opinion survey on Japanese researchers and corporate employees showed that standards' documents are helpful in R\&D planning as reference documents are (Nagaoka and Tsukada, 2009). This result refutes the conventional notion that a standard is useful for only an existing product's manufacture. Standards are also helpful in R\&D focused on new products. The opinion survey also showed that the view that standards are helpful was higher in the electric machinery industry. However, the limitation of the survey is that it is an opinion survey, hence statistical analysis between input factors and output factors is not provided and the practical application of the results from a management perspective is not easy. One of the aforementioned objectives is, therefore, to carry out the difficult task of quantitative analysis.

In addition, Tokumasu and Watanabe (2008) pointed out that the GSM mobile phone network played an important role in the transformation of the national innovation system of Finland in 1990s. The GSM mobile phone network uses standardised technologies, which are believed to have played an important role in the national innovation found in Finland during this time-period (Tokumasu and Watanabe, 2008).

This research attempts to observe the effect of standards on the industrial sector base rather than for specific products.

\section{Patents and Innovation}

Patents are an important source of innovation, but not all innovations are patented.

Journal of Technology Management for Growing Economies, Volume 4, Number 2, Oct 2013 
Corporations sometimes avoid patenting in order to protect trade secrets, especially in the case of process innovation. About 70 percent of new products, however, are patented to gain a competitive advantage (Ministry of Education, Culture, Sports, Science and Technology, 2004). Because the number of patent applications is a good indicator of the level of corporate innovativeness, the relationship between patent applications and innovativeness has been used in previous research as an analytical framework. In the present research paper, patent applications and corporate innovativeness are assumed to have the same relationship as that described by Cefis and Orsenigo (2001).

\section{Patents and R\&D}

Patents are thought to be the result of R\&D efforts and function as a source of innovation. Therefore, 'patents can be considered as an intermediate step between R\&D and innovation' (Organisation for Economic Cooperation and Development, 2009). It is generally assumed that patented inventions correlate with R\&D expenses. Acs and Audresch (1989) showed that patents provide a reasonably reliable measure of innovative activity and correlate positively with $R \& D$ expenditures. $R \& D$ spending has a positive relationship with the number of persons involved in $R \& D$ activities. According to previous data (Ministry of Education, Culture, Sports, Science and Technology, 2009), around 40 percent of total R\&D expenses can be attributed to $R \& D$ personnel costs in the case of Japanese industries.

\section{METHODOLOGY}

\section{Hypothesis}

Based on the review of literature it is hypothesised that IP-Related Standardisation Activities (IPRSA), IPRA and R\&D activities have a positive correlation with innovation in both the electric machinery industry and with all the industries in Japan. For the evaluation of innovation activities, patent applications are used as a proxy as in Figure 1 since patent applications are a good indicator of innovation level (Acs and Audresch, 1989).

Hypothesis: IPRSA, IPRA and R\&D activities have positive correlations with innovation in both the electric machinery industry and all industries in Japan.

This hypothesis is tested by evaluating Pearson correlation coefficients, which helps in determining the effect of R\&D in comparison to IPRSA and IPRA on the number of patent applications.

Journal of Technology Management for Growing Economies, Volume 4, Number 2, Oct 2013 
Tamura, S.
Input factors

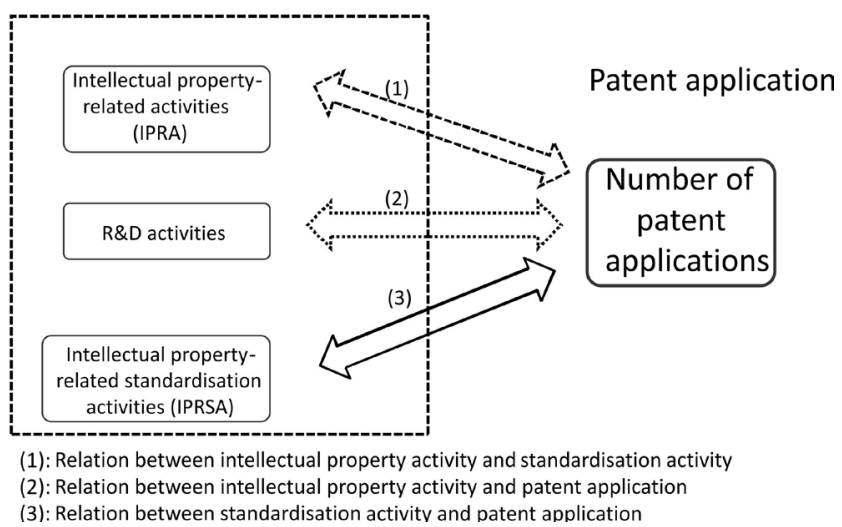

Figure 1. Relationships between input and output factors

\section{Hypothesis Testing}

For the validation of the hypotheses, the author uses Pearson correlation coefficient analysis rather than multiple regression analysis, since the development of a numerical evaluation equation and detection of the cause and effect among these three factors are not in the scope of this research. In addition, this treatment is appropriate in this research because in this analysis, (see Fig. 1) all input factors have the same dimension and unit relating to human resources (i.e. the number of persons) in IPRA, R\&D activities and IPRSA. The resulting Pearson correlation coefficients for the three factors against the number of patent applications are comparable and applicable for further discussion.

The relationships of SRA with patent applications, and IPRA with R\&D, by using the number of PIPRSA as a proxy for SRA, the number of PIPRA as a proxy for IPRA and the number of $R \& D$ personnel as a proxy for $R \& D$ activities is explored. For evaluating the effects of SRA, using the number of persons engaged in standardisation related activities (PSRA) would be preferable. However, as the level of SRA in organisations cannot be obtained directly from the SIPRA, the number of PIPRSA was used instead of SRA. The relationships between the three factors are illustrated in Figure 1.

The correlation was calculated between patent applications and the three factors PIPRA, PIPRSA and R\&D personnel for the electric machinery industry and all industries in Japan. T-test is used to determine the level of correlation for these relationships, with the level of significance set at $\mathrm{p}=0.05, \mathrm{p}=0.01$ and $\mathrm{p}=0.001$. All calculations were performed using the statistical analysis tools of Microsoft Excel 2007. 


\section{Dataset Construction}

Datasets were prepared using raw data from SIPRA 2008 according to the guidelines listed below (Tamura, 2010).

(i) Data on individuals who did not work as part of a larger organisation were removed from the dataset because the aim of this study is to examine effects within organisations.

(ii) Only complete data on organisations, including all four factors (patent applications, PIPRA, PIPRSA and R\&D personnel) were included in the dataset. Observations with incomplete data were excluded.

(iii) Data were removed from the data set if the number of PIPRSA was larger than the number of PIPRA because such data are due to respondent error. The intention of SIPRA is to determine the number of persons engaged in SRA as a subcategory of IPRA. Therefore, the number of SRA within IPRA should be smaller than that of IPRA.

All together, the compiled dataset the year 2008 contained 2,144 out of 3,375 SIPRA responses for all organisations. After sorting these 2,144 observations, 319 observations for organisations in the electric machinery industry remained. An overview of sample size by year and industry is presented in Table 1.

Table 1: Sample size for each dataset in 2008

\begin{tabular}{|c|c|c|}
\hline $\begin{array}{c}\text { Sample size of all } \\
\text { industries }\end{array}$ & $\begin{array}{c}\text { Sample size of electric ma- } \\
\text { chinery industry }\end{array}$ & $\begin{array}{c}\text { Total number of survey } \\
\text { responses }\end{array}$ \\
\hline 2,144 & 319 & 3,375 \\
\hline
\end{tabular}

Table 2 shows summary statistics including the mean number of PIPRA, PIPRSA, R\&D personnel and patent applications for all industries and for the electric machinery industry in Japan. Regarding the indicator of patent-related applications, organisations in the Japanese electric machinery industry had nearly twice the mean number of patent applications and PIPRA compared to organisations in all industries in Japan. In addition, the number of PIPRSA in the Japanese electric machine industry was 1.5 -fold that in all industries in regards to the standardisation-related indicators in 2008. On the other hand, regarding the $\mathrm{R} \& \mathrm{D}$ personnel, the Japanese electric machinery industry had almost the same mean number of $R \& D$ personnel as all industries. According to the raw data from SIPRA, the mean number of $R \& D$ personnel per corporation is 312 for all industries and 245 for the electric machinery industry.
$\mathrm{R} \& \mathrm{D}$ and Standardisation 
Tamura, S.
Table 2: Summary statistics for input and output factors in the electric machinery industry and all industries in Japan

\begin{tabular}{|l|c|c|c|}
\hline & $\begin{array}{c}\text { All industries } \\
(\text { mean }) \\
(\mathrm{A}) \\
(\mathrm{n}=2,144)\end{array}$ & $\begin{array}{c}\text { Electric machinery } \\
\text { industry (mean) } \\
(\mathrm{B}) \\
(\mathrm{n}=319)\end{array}$ & $\begin{array}{c}\text { Ratio } \\
(\mathrm{B} / \mathrm{A})\end{array}$ \\
\hline $\begin{array}{l}\text { Patent applications } \\
\text { per organisation }\end{array}$ & 85.685 & 172.296 & 2.01 \\
\hline $\begin{array}{l}\text { Number of PIPRA per } \\
\text { organisation (FTE) }\end{array}$ & 6.194 & 11.459 & 1.85 \\
\hline $\begin{array}{l}\text { Number of PIPRSA per } \\
\text { organisation (FTE) }\end{array}$ & 0.858 & 1.309 & 0.92 \\
\hline $\begin{array}{l}\text { Number of R\&D per- } \\
\text { sonnel per organisation } \\
\text { (FTE) }\end{array}$ & 306.629 & 283.851 & \\
\hline
\end{tabular}

\section{RESULTS}

The calculated correlation coefficients are listed in Table 3.

Table 3: Correlation between patent applications and intellectual propertyrelated activity, intellectual property-related standardisation activity, and $R \& D$ personnel in the electric machinery industry and all industries in Japan

\begin{tabular}{|l|l|l|l|l|l|l|l|l|}
\hline & & $\begin{array}{l}\text { Patent } \\
\text { ap- } \\
\text { plica- } \\
\text { tion }\end{array}$ & $\begin{array}{l}\text { Intellectual } \\
\text { property-related } \\
\text { activities } \\
\text { (PIPRA) }\end{array}$ & \multicolumn{2}{|l|}{ R\&D Personnel } & \multicolumn{2}{|l|}{$\begin{array}{l}\text { Intellectual } \\
\text { property -related } \\
\text { standardisation ac- } \\
\text { tivities (PIPRSA) }\end{array}$} \\
\hline $\begin{array}{l}\text { All in- } \\
\text { dustries }\end{array}$ & $\begin{array}{l}\text { Patent } \\
\text { applica- } \\
\text { tions }\end{array}$ & $1 * * *$ & $0.7746^{* * *}$ & $(1)$ & $0.3407 * * *$ & $(2)$ & $\begin{array}{l}0.1955 \\
* * *\end{array}$ & $(3)$ \\
\hline $\begin{array}{l}\text { Electric } \\
\text { ma- } \\
\text { chinery } \\
\text { industry }\end{array}$ & $\begin{array}{l}\text { Patent } \\
\text { applica- } \\
\text { tions }\end{array}$ & $1 * * *$ & $0.8987^{* * *}$ & $(1)$ & $0.5891^{* * *}$ & (3) & $0.3084 * * *$ & $(3)$ \\
\hline
\end{tabular}

\section{Correlations for all industries}

There is a strong positive correlation between patent applications and IPRA and a weak positive correlation between patent applications and R\&D activities. The strength of the relationship according to the correlation coefficient is

Journal of Technology Management for Growing Economies, Volume 4, Number 2, Oct 2013 
greatest for PIPRA, followed by R\&D and then PIPRSA.

\section{Correlations for the electric machinery industry}

A strong positive correlation is found between patent applications and IPRA. The analysis also reveals a strong positive correlation between $R \& D$ personnel and patent applications and a weak positive correlation between patent applications and PIPRSA. The strength of the relationship according to the correlation coefficient is greatest for PIPRA, followed by R\&D and then PIPRSA.

In all the cases in provided in Table 3, the correlation coefficients of the electric machinery industry were higher than those of all the industries in Japan. In addition, for both industry groupings, the strength of the correlation coefficients was greatest for PIPRA, followed by R\&D personnel and then PIPRSA.

\section{DISCUSSION}

\section{Correlation coefficient analysis}

It was hypothesised that IPRSA, IPRA and $R \& D$ have significant positive correlations with innovativeness in both the electric machinery industry and all the industries in Japan. The results support the hypothesis except in the case of IPRSA for all the industries in Japan.

First, amongst R\&D, IPRA and IPRSA, both R\&D and IPRA have a positive relationship with patent applications in both the electric machinery industry and all the industries in Japan. About R\&D, the correlation coefficient between patent applications and R\&D for the electric machinery industry $(0.58)$ and all the industries (0.34) indicates a significant correlation between the two factors. The electric machinery industry, therefore, shows a stronger correlation for R\&D than all the industries, a result which implies that the electric machinery industry has a greater propensity for patent applications than all the industries. As for IPRA, the correlation coefficients found between patent applications and IPRA for the electric machinery industry (0.89) and all the industries (0.77) indicate a strong correlation in both the electric machinery industry and all the industries in Japan.

Second, of all the factors considered, the relationship between IPRSA and patent applications in Japanese industry as a whole has the weakest relationship (correlation coefficient of 0.19), whereas for the electric machinery industry, the correlation between patent applications and PIPRSA is significant (correlation coefficient of 0.30). Using the number of PRSA as a proxy for SRA, the resulting correlation coefficient implies that SRA has a positive relationship with corporate innovativeness. Consequently, the relationship between

Journal of Technology Management for Growing Economies, Volume 4, Number 2, Oct 2013
$\mathrm{R} \& \mathrm{D}$ and Standardisation 
Tamura, S.

standardisation and innovativeness is positive.

Overall, the results here indicate that R\&D is more influential than IPRSA on patent applications and thus plays a greater role than standardisation activities in corporate innovativeness. With regard to the magnitude of the correlations observed, the correlation for IPRA is the largest, followed by R\&D and then IPRSA, for both the electric machinery industry and all the industries.

For quite some time, the standardisation activities were not thought of in the context of evidence-based research, but were instead considered in the examination of negotiation skills. This obstacle has been very difficult to be overcome in past research, and hindered the study of standardisation. On the other hand, the study of patents is now widespread and recognised as an important field in innovation research. This is largely because the patent data can be gathered in sufficient volumes and with a consistent format to allow statistical analysis. Patents afford legal ownership but standards do not, a difference that leads to different levels of social attention on the two issues. To date, research on standardisation has not been fully carried out as dataoriented research, which in the future will hopefully clarify the cause and effect relationships more directly. The present research provides a means for making standardisation research more evidence-based and the results will benefit evidence-based evaluation of standardisation activities within corporations.

\section{CONCLUSIONS}

The three input factors examined in this paper viz., R\&D, IPRA and IPRSA turn out to have significant relationships with patent applications and corporate innovativeness in the Japanese electric machinery industry. Specifically, our findings on the aforementioned three research objectives from the introduction section are as follows:

Objective 1

- To quantify the impact of number of persons working on standardisation activities on the number of patent application. It turns out that standardisation activities are useful for patent applications since correlation coefficient 3 (correlation coefficient between patent applications and IPRSA) is positive. In addition, the degree is medium in the electric machinery industry since the Pearson correlation coefficient is 0.3081 , although it is weak in all industries as the Pearson correlation coefficient is 0.1955 . Both standardisation and R\&D activities have a significant impact on patent applications in the Japanese electric machinery industry.

Objective 2

Journal of Technology Management for Growing Economies, Volume 4, Number 2, Oct 2013 
- To compare the impact of number of persons working in R\&D and number working in standardisation on patent applications. In the Japanese electric machinery industry, the correlation of R\&D activities with patent applications is twice as large as that of standardisation activities with patent applications. The finding that the correlation between standardisation and patent applications was only half the level (c26orrelation coefficient $=0.3084$ ) of that between R\&D and patent applications (correlation coefficient $=0.5891$ ) was not anticipated. At the same time, absolute value of the coefficient of standardisation (correlation coefficient $=0.3084$ ) was much larger than anticipated.

Objective 3

- To compare the different impacts of standardisation on patent applications between industries; the electric machinery industry in particular.

The different impacts of standardisation activities by industry are indicated using the correlation coefficient values. As in seen in Table 3, the correlation coefficient of PIPRSA is different between all industries (correlation coefficient $=0.1955$ ) and the electric machinery industry (correlation coefficient $=0.3084$ ). This also implies that in the service industry the effect of standardisation is strong since ICT services are one of the main business domains of the electric machinery industry today. In other words, in the service industry, standardisation is expected to have a positive impact on innovation because the electric machinery industry is strongly connected with the ICT services industry.

\section{IMPLICATIONS}

The finding that the absolute value of the coefficient of standardisation is much larger than anticipated may be beneficial in the effective allocation of human resources for fostering corporate innovativeness. This result also implies that allocating human resources to standardisation-related sections is worthy of consideration. This is because, in general, the absolute average number of PIPRSA is much smaller than that of R\&D personnel in corporations. In other words, this means that allocating more staff to a standardisation related division will enhance corporate innovativeness more than previously expected.

\section{LIMITATIONS AND FURTHER WORK}

The relationship between standardisation as a part of IP activities and patent applications appears to be positive. The data used on standardisation activities are, however, from Japan only. To confirm the validity of the results, it is desirable to establish a monitoring system to gather comparable information 

both developed countries and developing countries, and the profits of the industry account for a large part of national growth in many countries. Thus, such data gathering systems would provide much useful information.

\section{Abbreviations}

FTE: Full-Time Equivalent

IP: Intellectual Property

IPRA: IP-Related Activities

IPRSA: IP-Related Standardisation Activities

ISO: International Organization for Standardization

ITU: International Telecommunication Union

JPO: Japan Patent Office

PIPRA: Persons engaged in IP-Related Activities

PIPRSA: Persons engaged in IP-Related Standardisation Activities

PSRA: Persons engaged in Standardisation Related Activities

SDOs: Standard Development Organisations

SIPRA: Survey of IP-Related Activities

SRA: Standardisation-Related Activities

\section{ACKNOWLEDGEMENT}

The study was financially supported by a grant from Waseda University, Tokyo. The author appreciates the effort of the editors of JTMGE. Any remaining errors are those of the author.

\section{REFERENCES}

Acs, Z. J. and Audresch, D. B. (1989) 'Patents as a measure of innovative activity', Kyklos, 42:2, pp. 171-180. http://dx.doi.org/10.1111/j.1467-6435.1989.tb00186.x.

Blind, K. and Jungmittag, A. (2008) 'The impact of patents and standards on macroeconomic growth: A panel approach covering four countries and 12 sectors', Journal of Productivity Analysis, 29, pp. 51-60. http://dx.doi.org/10.1007/s11123-007-0060-8.

Cefis, E. and Orsenigo, L. (2001) 'The persistence of innovative activities: a cross-countries and cross-sectors comparative analysis', Research Policy, 30, pp. 1139-1158. http://dx.doi. org/10.1016/S0048-7333(00)00139-6.

David, P. A. (1985) 'Clio and the economics of QWERTY', American Economic Review, 75:2, pp. 332-339.

Gandal, N., Gantman, N. and Genesove, D. (2007) 'Intellectual property and standardisation committee participation in the US modem industry' in Greenstein, S. and Stango, V. (eds.), Standards and Public Policy, New York, Cambridge University Press, pp. 208-230.

International Organization for Standardization (ISO) (2006) ISO Members 2006, Geneva, ISO. Japan Patent Office (2008) Results of the Survey of Intellectual Property-Related Activities 
2007, Tokyo, JPO (in Japanese).

Ministry of Education, Culture, Sports, Science and Technology, National Institute of Science and Technology Policy (2004) Statistics on Innovation in Japan, Report on the Japanese National Innovation Survey, Tokyo, NISTEP. (in Japanese)

Ministry of Education, Culture, Sports, Science and Technology (2009) Monbukagakutoukeiyouran [Statistical Abstract]. Tokyo, MEXT. (in Japanese)

Nagaoka,S. and Tsukada, N.(2009) 'Standard-making R\&D and Standard-using R\&D: A first look at their characteristics based on inventor survey', Hitotsubashi Business Review, 57, pp. 50-65. (in Japanese)

Organisation for Economic Co-operation and Development (2002) Frascati Manual 2002: Proposed Standard Practice for Surveys on Research and Experimental Development, Paris, OECD.

Organisation for Economic Co-operation and Development (2009) OECD Patent Statistics Manual, Paris, OECD.

Stango,V. (2004) 'The economics of standards wars', Review of Network Economics, 3, pp. $1-19$.

Tamura, S. and Matsuda, H. (2008) 'Policy action for strategic international standardization (Kokusai hyoujun Senryakuni Kakawaru Seisakuteki Torikumi)', Journal of the Japan Society of Precision Engineering, 74, 1. (in Japanese). http://dx.doi.org/10.2493/ jjspe.74.12.

Tamura, S. (2010) 'Correlation between standardisation and innovation from the viewpoint of intellectual property activities: Electric machine industry and all organisations in Japan', Proceedings of the Conference of Portland International Conference on Management of Engineering and Technology 10 (PICMET 10), IEEE Explore database.

Tamura,S. (2012) 'Quantitative Measurement of Standardization Activities in Organizations', paper presented at the Fourth International Workshop 'Evaluation of Technology and Standards' (Center for Intergenerational Studies-RIETI), Hitotsubashi University, Tokyo. (online) (cited 1 June 2012). Available from<URL: http://cis.ier.hit-u.ac.jp/Japanese/ society/120412houtokeizai/Tamura.pdf>

Tokumasu, S. and Watanabe,C. (2008) 'Institutional structure leading to the similarity and disparity in innovation inducement in EU 15 countries-Finnish conspicuous achievement triggered by NOKIA's IT Driven Global Business', Journal of Services Research, 8:1, pp. $5-42$.

Dr. Suguru Tamura, Waseda University, Tokyo, Japan. Email: suguru. tamura@nifty.com.
$\mathrm{R} \& \mathrm{D}$ and

Standardisation 